\title{
Legal Translation Versus Legal Interpretation. A Legal-Theoretical Perspective
}

\author{
Mateusz Zeifert ${ }^{1}$ (D) Zygmunt Tobor $^{1}$ (D)
}

Accepted: 16 March 2021 / Published online: 27 March 2021

(c) The Author(s) 2021

\begin{abstract}
In this article we investigate the relationship between legal translation and legal interpretation. The common wisdom is that these activities are closely related, but the nature of that relationship remains disputable. We adopt the perspective of legal theory-as opposed to the perspective of translation studies-which seems to be underrepresented in the literature of the subject. We start with distinguishing between the two notions of legal interpretation: the wide sense (interpretation as understanding) and the narrow sense (interpretation as problem solving). We argue that the relationship between legal translation and legal interpretation changes significantly depending on the notion of legal interpretation that is assumed. The wide sense is often assumed by translation scholars and it renders legal interpretation as a necessary prerequisite for legal translation. Jurists, on the other hand, usually assume the narrow sense which renders legal interpretation and legal translation as two distinct activities with some shared features. We then focus on four issues of legal interpretation in the narrow sense: the types of legal interpretive problems, the creation of legal interpretive problems, the methods of legal interpretation, the resolution of legal interpretive problems. We conclude with a detailed comparison of legal translation and legal interpretation in the context of those four issues.
\end{abstract}

Keywords Legal interpretation · Legal translation $\cdot$ Legal Theory $\cdot$ Legal argumentation

Mateusz Zeifert

mateusz.zeifert@us.edu.pl

Zygmunt Tobor

zygmunt.tobor@us.edu.pl

1 Faculty of Law and Administration, University of Silesia, Katowice, Poland 


\section{Introduction}

In this article, we intend to investigate the relationship between translation and interpretation in a legal context. The common wisdom is that legal translation and legal interpretation are closely related [26: 262; 16:376;2: 109]. ${ }^{1}$ The reasons for this are self-evident. They both have a legal text as their object, and the meaning of a legal text is the central notion for both of them [2: 109]. The exact nature of their mutual relationship is not clear, however. Some authors classify them as two different types of "legal-linguistic operations" [20: 270]. Others suggest that they are essentially "two sides of the same coin" [16: 375]. Some render legal interpretation as "the most important part of legal translation" [11:5], whereby no translation is possible without interpretation [30: 150]. According to a similar view, "legal translation is a special case of legal interpretation" [1: 55]. Conversely, others claim that legal interpretation is actually a peculiar kind of translation, namely "intralingual translation" [49: 180] or that translation can be viewed as a model for legal interpretation [29: 1171]. Still, the prevailing view is that translators should refrain from interpreting legal texts [2: 109; 5, 46, 53: 64].

These theoretical discrepancies are certainly fuelled by the fact that both translation and interpretation also have a much broader, non-legal significance. From a more general perspective, translation may be conceived as an "interpretive practice" [30: 149] or "interpretation of verbal signs by means of some other language" [27: 145]. The philosopher H.-G. Gadamer famously claimed that "every translation is at the same time an interpretation. We can even say that the translation is the culmination of the interpretation that the translator has made of the words given him" [20: 386]. Similarly, the prominent semiotician Umberto Eco believed that translation is a "limited type of interpretation" [26: 263] or "a special kind of interpretation" [12: 130]. By contrast, another radical view, interestingly also attributed to Gadamer, holds that essentially "all communication is translation" [44: 187] and seeks to expand translation theory "into a comprehensive theory of language" [44: 187].

All these claims, as conflicting as they are, are too vague to be easily rejected and too general to have any practical value. In our opinion, much of the inconsistency of different views about the relation between legal translation and legal interpretation comes from the indeterminacy of the meaning of the term interpretation. Bajčić has made a valid point that "interpretation in law is not necessarily the same as interpretation in translation studies [2: 109]. As a matter of fact, the subject matter so far has been discussed mainly amongst translation scholars who, even if they have sufficient legal training or experience in legal drafting, are not necessarily familiar with the theoretical and practical subtleties of legal interpretation. This may, and sometimes does, lead to the use of imprecise or confused terms, deficient or outdated classifications, etc. This should come as no surprise, as specialists from all relevant disciplines, including translation scholars, terminologists, linguists and comparative lawyers, "tend to approach legal translation through a methodological lens and in line

\footnotetext{
1 Note that in English the word interpretation means also 'oral translation'.
} 
with interests prevalent in their disciplines" [6: 2]. Our goal, therefore, is to provide a legal-theoretical perspective on the relationship between legal translation and legal interpretation.

\section{Terminological Clarifications}

\subsection{The Concept of Legal Translation}

It is necessary to begin with some terminological clarifications. The concept of legal interpretation is the central topic of this article and will be discussed in detail. However, the concept of legal translation that we adopt also demands some clarification. We take a definition by Galdia as a point of departure. According to him, legal translation is "the procedure in which legal speech acts of the source language are transformed into meaningful and equivalent legal speech acts in the target language" [20: 271]. Setting aside the problem of oral interpretation, it may be noted that legal speech acts are normally expressed in legal texts. Therefore it is crucial to distinguish legal texts from non-legal texts. This is a point of contention between various translation theorists. Some emphasise the textual functions of a text, others the discursive parameters of a communicative situation [42: 262]. Numerous typologies of legal texts have been presented, resulting in the inclusion or exclusion of certain categories, i.e. private documents used in court proceedings as part of documentary evidence [see: $8: 7-13 ; 25: 178-179 ; 42$ : 262-265]. Due to such discrepancies, some authors have criticised the distinction between legal and non-legal texts, and proposed a distinction between the legal and non-legal function of a translation instead [16: 384; 8: 8]. Still, we find most definitions of legal translation to be prototypical rather than criterial, meaning that they do not determine rigid boundaries of the activity in question [see: 59: 95-98]. The prototypical, or the most representative, type of legal texts are normative texts i.e. statutes, codes, constitutions, regulations, international treatises, etc. [42: 262-263; 25: 178-179; 16: 275]. Accordingly, this will be our focal point. The discussion below refers primarily to normative texts and secondarily to other binding texts, i.e. private contracts, wills, and-to some extent-judicial and administrative decisions, as well as notarial documents. Nonbinding texts, such as litigation documents, legal scholarly works, etc. are generally outside the scope of our interest, although some findings may apply to them as well.

\subsection{The Concept of Legal Interpretation}

Having discussed the concept of legal translation, we can now concentrate on the crucial concept of legal interpretation. As has already been mentioned, interpretation is a vague and polysemous term, meaning that it has numerous senses that are semantically connected but nevertheless different [i.e. see the discussion in 18: 1237-1243; 56: 13-36]. In legal theory, numerous typologies and classifications have been proposed. One such classification comes from the Polish legal philosopher Jerzy Wróblewski [4: 12]. He identified three main senses of interpretation: the 
widest sense (sensu largissimo), the wide sense (sensu largo) and the narrow sense (sensu stricto). Interpretation in the widest sense covers all sorts of understanding of cultural objects. Interpretation in the wide sense refers to ascribing meaning to linguistic communication (spoken or written). In other words, to interpret sensu largo means simply to understand language. Interpretation in the narrow sense occurs only whenever there are doubts about the meaning of a particular act of linguistic communication. This complies with the observation by Frederick Schauer that "we normally reserve the word»interpretation « for those applications of language that present some sort of problem" [quoted in 15: 476]. The latter sense introduces a distinction between interpretation as a deliberate, discursive activity on the one hand and mere understanding (also called direct understanding) on the other. An interesting parallel with translation may be noted: "[l]ike the interlanguage translation of texts, interpretation in law proceeds first by understanding the sense or meaning of the text at issue in its original context" [29: 1211]. This view has been advocated by many prominent contemporary legal scholars: "[u]nderstanding is an ability, and interpretation is an activity" [14: 461], "[i]nterpretation is possible only against a background of unreflective linguistic practice. Interpretation is one of a number of reflective activities we engage in when conventional meanings are called into question" [39: 54]. It has deep philosophical roots that we cannot discuss here [see i.e. 14].

Legal (or judicial, or juristic, or statutory, or operative) interpretation is often construed as interpretation in the narrow sense [4: 8-16]. It conforms to the observation that legal rules are mostly applied to cases in a quasi-mechanical manner, without the need to elaborate on their meaning. These are the so-called "easy" cases. Only when doubts arise as to the application of a rule in a particular factual situation is interpretation called for. These are the so-called "hard" cases that require making interpretive decisions [14: 466]. It should be noted that this distinction is of a pragmatic_-as opposed to semantic — nature, and the same legal rule may require interpretation in one case and be merely understood (i.e. without interpretation) in another [23: 82].

\section{Legal Translation and Interpretation sensu largo}

How does the above conceptual distinction alter the answer to our main question about the relation between legal translation and legal interpretation? If we adopt the wide sense of interpretation (sensu largo), i.e. interpretation as understanding, it will mean that interpretation is a prerequisite for legal translation. Such an approach is indeed common in literature on the subject: "In a very basic sense we can say that legal interpretation is text-based rational activity that seeks to give rational meaning to a legal text, or an expression in a legal text [26: 263]; "translation, like any act of reading, necessarily involves interpretation" [25: 182]; "[t]he aim of interpretation is essentially to understand" [12: 130]. The reason for this is that translation "is based on an understanding of two texts: a source text which is to be translated and a target text which is the result of the actual translation process" [20: 272]. A text simply cannot be translated if it has not been previously understood: "the first 
stage in successful translation is to understand the source text fully, and only then can the production of a target text follow" [11: 2]. This approach conforms with the common sense idea that translation in general consists in understanding and reexpressing the meaning of a given communication [27: 64]. ${ }^{2}$

Needless to say, legal texts are notorious for being difficult to comprehend. "[L] egal language tends to remain complicated and hermetic" [33: 129]. Among the many factors that lead to this result are: heavy use of technical vocabulary, heavy use of archaic, formal or unusual words, impersonal constructions, overuse of nominalisations and passive voice, and graphical organisation of text [55: 203-210]. These formal features of legal text, though possibly intimidating for a lay person, should not scare off any professional translator. However, there are additional layers of difficulties in understanding legal texts. Ultimately "law is not a discipline of words, but of concepts" [2: 7], and concepts - not words - are "crystallisations of legal rules" [33: 137]. A translator, in order to understand a legal text, must grasp the concepts that are encapsulated in it. To do this, they must understand legal institutions created with those concepts [20: 278]. And legal institutions are inseparable from the legal systems in which they function: "the interconnections within each legal system as well as the legal culture in general influence the meaning and practical impact of legal concepts" [28: 7]. ${ }^{3}$ Consequently, linguistic competence does not constitute a sufficient condition of understanding legal texts [54: 15], because a "legal text derives its meaning from a particular legal system or systems [46: 5]. ${ }^{4}$ Hence, "the level of difficulty of a legal translation does not primarily depend on linguistically determined differences, but rather on structural differences between legal systems" [20: 274].

Obviously, this state of affairs poses a challenge for translators of legal texts, demanding from them an expertise not only in languages, but also in law [22: 259, 40: 145, 44: 192]. In other words, "translators must step into the realm of law" [26: 262] and "know how lawyers, including judges and lawmakers, think and write, and how they write the way they do" [8: 5]. This aspect of legal translation has been duly acknowledged in translation studies. Ramos has proposed a detailed model of legal translation competence, focusing on thematic and cultural subcompetences that include "knowledge of legal systems, hierarchy of legal sources, branches of law and main legal concepts; an awareness of asymmetry between legal notions and structures in different legal traditions" [41: 12]. Similar efforts, inspired by translation hermeneutics, were undertaken by Piecychna, who complains that the importance of understanding the source text is underestimated even by professional translators [40: 155]. According to her, the legal translation thematic subcompetence should comprise of "understanding and knowledge of the differences between various legal

\footnotetext{
${ }^{2}$ We expect that this assumption may come to be questioned on the grounds of recent technological advances (i.e. Google translate and similar devices), but that is not our point of interest (nor of our scholarly competence).

3 The feature of being "system-bound" is not unique to law. In fact, it is shared by many other disciplines, including religion, political science and philosophy [26: 180].

${ }^{4}$ Certainly, translation in general also requires more than mere linguistic competence.
} 
systems and legal cultures; the ability to compare various foreign legal systems with reference to the specificity of the translation task; understanding and knowledge of different sub-fields of law, such as civil law, criminal law, family law, international law, trade law, etc.; the ability to interpret and analyze a legal text" [40: 154]. Some scholars have suggested that cooperation between translators and lawyers can guarantee the best results [26: 268], while others have advocated for extended legal training for translators [11:10-12;41: 18-19]. The general consensus is that legal translation is, at heart, an interdisciplinary endeavour [see i.e. 8, 22, 41, 42]. There is even some empirical evidence that translators who have a law degree do significantly better at translating legal texts than those who lack professional legal education [30: 210-211, see also: 40: 147].

To conclude this part of the article: if we adopt a wide sense of interpretation (sensu largo), then we have no choice but to agree that all legal translation must necessarily be preceded by an act of legal interpretation. This conclusion, as obvious as it is, nevertheless places a heavy burden on translators (and translation theory), given both the linguistic and extra linguistic characteristics of the legal domain.

\section{Legal Translation and Interpretation sensu stricto}

Things change if we adopt a different sense of interpretation, namely interpretation in the narrow sense (sensu stricto). This concept introduces a distinction between understanding and interpretation. As a result, although translators are obviously still required to understand legal texts in order to do their job, they do not necessarily need to interpret them.

Such a narrow view of legal interpretation is also represented among translation scholars. However, opinions on whether translators may or should engage in such activity are divided. Cao claims that "[t]he legal translator does not read and interpret the law the way a lawyer does" [8: 5]. Similarly, Šarcevic points out that "it is generally accepted that the translator must understand the source text, but not interpret it in the legal sense [46: 5]. The distinction between understanding and interpretation is directly addressed by Piecychna: "But it is not only understanding that plays an important role in the translational process. The act of interpretation can also be distinguished as having a significant role. Having understood a text, a legal translator's task is to interpret the source message and transpose it into the target message" [40: 155]. It is important to note, however, that no criteria for this distinction are provided.

Such criteria have been offered by some other scholars and it is necessary to critically assess them at this point. Chromá suggests that legal interpretation only comes into question whenever "the legal context is to be considered when looking for an adequate meaning" [11: 7]. Therefore she implies that in some (most?) cases, translators of legal texts do not have to consider the legal context in order to find the appropriate meaning of a legal text. Such a claim is untenable. As follows from the analysis above, legal context is indispensable for understanding legal texts. In fact, the significance of legal knowledge is undisputed in legal translation theory, and it is rightly included in theoretical models of legal translation competence [16, 
$26,40,41]$. By contrast, Weyers states that a major difference between lawyers and translators (and presumably also between legal interpretation and legal translation) is that lawyers tend to take their point of departure in the meaning of words, whereas translators rather take larger textual units, such as the sentence or the section, as their point of departure [referred to by 16: 376]. We find such a difference to be purely methodological, not conceptual. Nevertheless, it is a step in the right direction, although it describes the effect rather than the cause. The latter is correctly identified by Husa, who notes that "a translator deciphers all of the text whereas legal interpretation is much more selective. In other words, only difficult or unclear parts of legal texts require interpretation, because in most cases the meaning of the words and sentences are rather unproblematic; in contrast, interpretation is needed only when there is uncertainty or a dispute about which legal meaning one can or should attribute to a text" [26: 263]. His findings fit quite well with the legal view presented above. Legal interpretation (i.e. interpretation sensu stricto) is selective not because lawyers, unlike linguistically educated translators, tend to focus on particular words, but because only particular words (or phrases, or sentences, etc.) pose interpretive doubts and therefore require legal interpretation. As Fallon puts it, "[a] $\mathrm{n}$ important challenge for legal interpretation is to resolve puzzlement, uncertainty, or disagreement about claims of legal meaning" [18: 1276]. In other words, legal interpretation in the sense discussed is not primarily a matter of communication, but rather of problem-solving. This leads us to ask four instructive questions: what are these problems?, how they are created?, how can they be solved?, and who can solve them?

\section{The Four Problems of Legal Interpretation}

\subsection{The Types of Legal Interpretive Problems}

There is no finite list of legal interpretive problems and their typologies vary; nonetheless, there are certainly some recurrent ones that are rather uncontroversial. These include: syntactic ambiguity, lexical ambiguity, ambiguity of reference (classification) and vagueness [52: 338]. The following examples were selected from various legal systems, which is a testimony to the universality of the typology in question:

a. Syntactic ambiguity: The provision grants a tax relief on "expenses incurred for (...) the purchase of individual equipment, devices and technical tools necessary for rehabilitation and facilitating life activities" [see: 58: 37-38]. Does the adjective "individual" refer only to "equipment" or to the whole phrase: "equipment, devices and technical tools"? In other words, must devices and technical tools also be individual in order to be tax-free? The syntax of the provision (i.e. the word order in the sentence) is ambiguous as it allows two linguistically plausible readings, not unlike Chomsky's famous example: "Flying planes can be dangerous" [10: 41-42].

b. Lexical ambiguity: A contract provides for the delivery of chicken. A dispute arose between the buyer and the seller as to the meaning of the word chicken. 
Does it mean a young chicken, suitable for broiling and frying, or any bird of the genus that meets contract specifications on weight and quality? [see: 47: 1-6] The word chicken is clearly polysemous in that it has (at least) two related, albeit distinct, senses, and consequently the language of contract allows two linguistically plausible readings.

c. Ambiguity of reference (classification): EU law vests the power to issue European Arrest Warrants onto judicial authorities of member states, without providing a definition of the term "judicial authority". As a result, national institutions assigned as "judicial authorities" by different member states vary to a great extent: from courts and judges to prosecutors' offices and police boards [see: 59: 100113]. There are simply no rigid linguistic criteria for classifying an institution as a "judicial authority" according to EU law, and this is how the ambiguity of reference occurs.

d. Vagueness: By statute, it is an offence to cause a child to be "neglected, abandoned, or exposed, in a manner likely to cause him unnecessary suffering or injury to health" [see: 15: 16-17]. Words like neglecting, abandoning, or unnecessary suffering are vague in that they do not specify the scope of their application. Instead, their application necessarily involves making evaluative judgments, i.e. how long does it take to leave a child without supervision to classify it as abandoning? or what level of mental discomfort is enough to be classified as suffering? Statutes in all languages abound with vague words and phrases, such as reasonable time, high probability, necessary means, significant amount, etc.

Note, however, that not all possible linguistic indeterminacy amount to legal interpretive doubts. Most issues are resolved by textual or extra-textual context, just as in everyday life. For example, nobody will notice the syntactic ambiguity of the sentence "Flying planes can be dangerous" if we utter it as a reaction to news about a plane crush. Similarly, a judge will not be bothered by the vagueness of the phrase "a significant amount of a psychotropic drug" if it was $4000 \mathrm{~kg}$ of amphetamine that was smuggled. These observations lead to the next question concerning the way in which interpretive problems are created.

\subsection{The Creation of Legal Interpretive Problems}

The common-sense view that "only difficult or unclear parts of legal texts require interpretation" [26: 263] is rather misleading. As the previous examples show, the need for legal interpretation is not triggered solely by linguistic features (ambiguity, vagueness, etc.) of the legal text, because context may do the job (and usually does). What triggers the need for legal interpretation are doubts whether the law, expressed in language, applies to a particular situation or-if we adopt the opposite perspective- - whether a particular event in the world fits a legally relevant category" [52: 338]. To put it in yet another way: legal interpretation is the "resolution of questions about what the content of the law is in its application to particular cases" [50: 321]. These questions may arise for different reasons, but usually they happen because of discrepancies between a legal rule and the facts of the case: "[m]ost disputes over 
the meanings of statutes are about the fit between events in the world and the words in the statute" [51: 50]. This leads us to acknowledging the role of a factual situation in legal interpretation. According to the hermeneutic tradition, the meaning of a legal text is only found in its application to a particular case [19: 334, 17: 633]. This approach has recently been named concurrent interpretation, as opposed to prospective interpretation [see: 57]. Other scholars draw a distinction between text-oriented interpretation or interpretation in abstracto on the one hand, and fact-oriented interpretation or interpretation in concreto on the other [see: 24]. This is actually a very compelling subject that exceeds our scope of interest in this article. Suffice it to say that as far as operative (i.e. judicial) interpretation is concerned, the factual situation is a crucial factor involved in generating interpretive doubts.

\subsection{The Methods of Legal Interpretation}

Legal interpretation has a specific method of its own, or so it is believed in translation studies [41: 15, 40: 147]. It is not an easy task to define such a method in a detailed manner, however. Undoubtedly, there is no shortage of rules of interpretation, known also as directives, maxims, canons, etc., used by lawyers practicing in various legal systems and catalogued by jurists. To a large extent they converge amongst legal cultures, at least within Western world [see: 4]. However, they are no more really than rules of thumb [52: 338]. In our opinion, they are best thought of as heuristic tools that provide framework for interpretive analyses, but in no way dictate the results of interpretation [see: 35].

In a classic paper, Karl Llewellyn argued that guidance by canons of interpretation is mere illusion and that in fact "there are two opposing canons on almost every point" [31: 401]. In addition to that, there is a deep theoretical disagreement about the ultimate goal of legal interpretation, particularly vivid in American legal thinking. For the intentionalists it is the reconstruction of the meaning intended by the legislator. For the textualists it is the reconstruction of the objective meaning of the legal text [see i.e. 32, 52]. The answer to this theoretical dilemma dictates the references that one is willing to consider during the process of interpretation. Apart from the most obvious one, namely the legal text in question, lawyers and judges consult various other evidence in their search for meaning. This may include other legal texts (including international treatises and supranational law), law books, law journals, previous judicial decisions, dictionaries and legislative history, as well as philosophical treatises, the Holy Scripture, popular literature, newspapers, polls, scientific reports and linguistic corpora.

\subsection{The Resolution of Legal Interpretive Problems}

Legal interpretation in the narrow sense is conducted mostly by legal professionals: lawyers, judges, etc. However, here an important distinction is in place. Legal interpretation may either be authoritative (i.e. legally binding) or not. This does not depend on methodological or other aspects of the interpretation itself, but purely on the institutional position of the interpreter. As Harvey notes, in law, not unlike 
in religious systems, "disputes over interpretation are settled by an official body (in this case, a court) which imposes a legally binding construction of a text" [25: 181]. Some legal scholars have even built the element of authoritativeness into their definitions of legal interpretation [see: 50: 1].

This element has such significance because of the effects it bears. An interpretative decision by a judge (or other public official) undertaken in a particular case is legally binding, meaning that it determines the rights and obligations of the parties involved. An interpretation of the same provision, identical in terms of method and result, undertaken by a lawyer (or a legal scholar, a politician, a journalist, etc.) bears no legal force. Another salient trait of legal interpretation (both authoritative and non-authoritative) is its persuasive character. Legal interpretation is rarely, if ever, conducted for purely cognitive purposes. It is embedded in a practical legal discourse and aimed at advancing a particular construction of the text in question, be it a constitution, a statute, an international agreement, a contract or a will. As put by Fallon, "standards for the determination of legal meaning are necessarily internal to legal practice" [18: 1243]. Even at conceptual level, legal interpretation is inherently tied to legal argumentation; it is indeed an "argumentative battle concerning meaning" [16: 385]. Using more philosophical categories we can say that legal interpretation requires adopting an internal point of view in the Hartian sense, namely a practical attitude of acceptance of a given legal system [see: 48]. A similar idea has already been expressed in legal translation studies [27: 264].

\section{Legal Translation and Legal Interpretation sensu stricto: A Detailed Comparison}

The above answers to the four questions regarding legal interpretative problems are by no means exhaustive. Their role is merely to serve as reference points for further discussion. Having formulated them, we can now compare legal translation and legal interpretation in more specific measures.

To begin with, translation affects whole texts or their parts, independent of the doubts or lack thereof. This is why, from a translator's perspective, legal interpretation seems "selective" [26: 263]. Of course, legal translators in their work are confronted with manifold difficulties [see: 22, 25, 40, 41], some of which may converge to the interpretive problems as identified in legal theory: ambiguity, vagueness, etc. It is very doubtful, however, that they have the legitimacy to eliminate them. Indeterminacy in legal texts is often deliberate [see 15]. In this respect, the legal text is comparable to a literary text, in which indeterminacy "is viewed not a defect but as an inherent feature which should be retained in translation" [25: 181]. Therefore, translators should not run the risk of upsetting the delicately achieved balance of a legal instrument by "attempting to clarify vague points, obscurities, and ambiguities" [46: 8]. If a translator eliminates ambiguity by choosing one possible meaning over another, they put themselves into the legislator's shoes (from the perspective of a judge) or in the judge's shoes (from the perspective of a legislator); neither 
role is designed for them ${ }^{5}$ : "[i]n regard to ambiguities, it is generally agreed that the translator has no authority to resolve an ambiguity in the source text as this could be an act of interpretation" [45: 92]. The same goes for vagueness. Most obviously, a translator is not supposed to eliminate vagueness by using a more precise term, because by doing so she would modify the normative content of the text [see: 34 : 93-99].

As a matter of fact, not all indeterminacy in legal text is deliberate. Most notably, ambiguity (both syntactic and lexical) is usually testimony to the legislator's incompetence [50: 18-19]. Still, the translator generally does not enjoy the legitimacy to correct such drafting errors, although the situation depends significantly on the institutional context and the type of legal text in question. Therefore we generally agree that "the translator must avoid value judgments (to the extent possible)" and that "the translator's task is to convey what»is said « in the source text and not what he/she believes it»ought to say«" [46: 5]. The problem here is that the indeterminacy of a legal text, except for the most obvious instances of syntactic ambiguity, is seldom identifiable outside of the context of a particular factual situation. We are sympathetic to Engberg's claim that a translator "must at all times discover what specific words and terms mean in the concrete situation" [16: 385]. However, there are several reasons why translators are usually deprived of such context. The skopos or purpose of a particular translation, i.e. defined in a translation brief, provides only some very general context. Consequently, translators may be unaware of the indeterminacy in the text they are working on, and may eliminate it unknowingly. As Harvey states, "indeed, it requires interpretation to identify ambiguity, decide it is deliberate, and choose to retain it in the translation" [25: 181].

In this context, it is worth mentioning the idea of translation universals. There appear to be certain general and universal tendencies that typically characterise translations rather than original texts, which are irrelevant of the language pairs involved or the type of the text, and which result rather from the inherent features of the translation process [7, 43]. These, according to Baker, include: explicitation (a tendency to spell things out rather than leave them implicit), simplification (a tendency to make the text more intelligible and resolve ambiguities), normalisation (a tendency to use typical expressions in lieu of atypical ones) and sanitation (a tendency to correct errors) [3; 7: 18-19]. The topic of translation universals is an interesting and controversial one, though we have neither the competence nor intention to elaborate on it here [see i.e. 9, 43]. However, it does seem that these features may be relevant for legal translation. The tendencies to correct supposed errors, eliminate ambiguities or make things explicit are likely to impact not only the intelligibility of the target text, but also its normative content. Still, the role of a translator is to translate the text, not to improve it [45: 92].

Many translation scholars insist that legal translators should be trained to interpret legal texts [25: 182, 40: 147, 41:13]. However, as has already been noted, there

\footnotetext{
5 A special case would be the institution of "co-drafting" known in bilingual and multilingual jurisdictions, such as Canada, Switzerland, or the European Union, which incorporates translators into the process of legislative drafting and thus officially puts them in legislator's shoes [see: 46: 5].
} 
is no single method of legal interpretation. The so-called "rules of interpretation" [41: 13] are merely heuristic tools that lose their value if isolated from the broader context of legal reasoning and argumentation. As mentioned, legal interpretation is an inherent part of legal practical discourse. This is well illustrated by the materials lawyers refer to in their interpretation. As Husa notes, "for legal interpretation, sometimes the key-elements for the interpretation come from outside of the text itself" [26: 264]. Many of them are legal-specific, i.e. previous judicial decisions (case law), other legal acts (known as "systemic interpretation") or legal values (known as "teleological" or "purposive" interpretation). To utilise such sources of reference in one's interpretation, it requires a profound knowledge of not only the legal text in question, but of the legal system as a whole.

Such knowledge is assumed in certain models of legal translation competence [see: 41: 13], and rightly so. The difficulty lies not in its level of sophistication or complexity, but rather in the highly practical nature of the knowledge. It can hardly be attained without participating in legal discourse. In other words, it requires an internal perspective, naturally adopted by a practising lawyer or a judge. A translator's perspective, on the other hand, is by default external. In Hart's terms, an external point of view refers to a person who is an observer "whose interest in the law is primarily theoretical, who simply wishes to describe how members of a group regard and respond to a set of rules and, perhaps, who wishes to make predictions as well" [48: 1159-1160]. This explanation conforms to the claims of translation theory, where the difference between legal interpretation and legal translation is rendered as a difference between two epistemic points of view [26: 264] and the translator is described as "an outsider not involved in the official and binding process of interpretation [...] an outsider to the discourse community" [16: 386].

The above statements should not conceal the actual impact of a translator's work on the meaning of legal texts. The end product of a translator's work is usually the starting point for an interpretive enquiry. Thus, it is obvious that a translator's choices may directly affect the outcome of legal interpretation [see examples in 1: 45-55]. For instance, "by favouring a certain type of equivalent, the translator effectively sends a signal to the courts as to how that term should be interpreted" [46: 7]. Terminological choices, of course, are not the only aspect of translated texts that may affect their future interpretation. Formal properties, such as the syntax of a provision, are also relevant [45: 162]. In fact, poor translation may cause interpretive doubts that would never have occurred in the original language [5: 11].

This state of affairs has been noted in translation theory. The traditional notion of a translator as a mere mediator between the source text producer(s) and the target text receiver(s) is being questioned. In line with the current trends in general translation theory, many scholars paint the picture of a legal translator as an independent "text producer" rather than a "bilingual typist" providing simple linguistic equivalence [16: 382, 25: 180, 45: 97, 46: 4]. Indeed, in some legal systems translators are thought to be "co-drafting laws rather than translating them" [21: 75]. In Canada, this approach is called "bijuralism" [13: 34-35], while in the European Union it is often referred to as "multilingual drafting" [53: 59-60]. Still, such a new conceptualisation of the translator's role not only fails to eliminate practical problems inherent in the translation process, but in fact it creates some more [53: 63-64]. It seems 
that we face a paradox: lawyers and judges, due to their embedment in practical legal discourse, have the tools to identify interpretive doubts, but do not have the power to eliminate them from legal texts. At the same time, the external epistemic position of translators means they generally lack the tools to identify interpretive doubts, but they do have the power (though not necessarily the legitimacy) to eliminate them from legal texts (namely target texts).

Finally, it is important to discuss the goal of legal translation versus the goal of legal interpretation. The former has been defined in many different ways. For Galdia, it is establishing "a relationship of equivalence between the source and the target texts" [20: 272]. For Pelage, it is creating the target text with "the same meaning potential as the original texts" [quoted by Engberg in 17: 376]. For Šarcevic it is producing "parallel texts that will be interpreted and applied uniformly by the courts" [46: 5]. Similarly, for Engberg, it is creating a text "that is interpreted in the same way by readers familiar with the target-language legal system as the source-language text is interpreted by readers familiar with the source-language legal system" [16: 375-376]. Chromá is even more specific, claiming that "the primary objective of legal translation is that the target recipient should be provided with as explicit, extensive and precise legal information in the target language as is contained in the source text, complemented (by the translator) with facts rendering the original information fully comprehensible in the different legal environment and culture" [11: 6].

The latter is often defined as finding or establishing the correct meaning of a legal text. However, given the concept of interpretation sensu stricto that has been used in this article, this equates with finding the correct answer to a particular interpretive doubt. In either case, there is a noticeable lack of agreement amongst jurists and legal theorists as to what counts as correct. This is clearly a consequence of the lack of any uniform concept of meaning that would be commonly accepted in legal discourse. For instance, Fallon distinguishes the following notions referred to by legal practitioners and scholars: “(1) semantic or literal meaning; (2) contextual meaning as framed by shared presuppositions of speakers and listeners, including shared presuppositions about application and non-application; (3) real conceptual meaning; (4) intended meaning; (5) reasonable meaning; and (6) interpreted meaning" [18: 1244-1245]. These "types of meaning" somewhat correspond to the methods of translation as listed by Newmark [36: 45-47], which include: word-for-word translation, literal translation, faithful translation, semantic translation, adaptation, free translation, idiomatic translation and communicative translation.

Although this paper is not the place to discuss the tangled issue raised above, it may be instructive to note one important similarity between legal interpretation and legal translation that pertains to this topic. It is their shared reliance on the concept of the author's intent. As Harvey observed, "the notion of authorial intent, long derided as the "intentional fallacy" by literary critics, is alive and well in both translation studies and legal studies" [25: 181]. Engberg claims that the task of both legal interpreter (i.e. a judge) and legal translator is to establish the meaning most probably intended by the utterer (i.e. text's author), although their perspectives and methodologies vary [16: 381, 387]. An important insight is made by Šarcevic. According to her, "the translator's task is to produce a text that preserves the unity of the single instrument, i.e. its meaning, legal effect, and intent" [46: 5]. She acknowledges, 
however, that these concepts are not identical, "[w]hereas the presumption of equal meaning is subordinate to that of equal effect, both are subordinate to the presumption of equal intent. Hence, the translator should strive to produce a text that expresses the intended meaning and achieves the intended legal effects in practice. In jurisprudence this usually implies the legislative intent (legislation), the intent of the States parties (treaties, conventions), or the will of the contracting parties (contracts)" [46: 5]. In translation studies, this idea is frequently discussed under the term fidelity [see i.e. 25: 180-181]. Interestingly, this term, along with its translation connotations, has also been imported to legal theory [see: 29].

At the same time, translation theory states that it is not impossible to conceive of more than one correct translation of a given text. As put-perhaps a little too harshly - by Kischel, "the question in legal translation is not which translation is right, but, more modestly, which one is less wrong."'[28: 7]. This is because "[c] orrectness must be determined by the extent to which the average reader for which a translation is intended will be likely to understand it correctly" [37: 1]. This is particularly noticeable in light of the Skopos theory, which places the communicative purpose of the text at the centre of the translator's enterprise [38: 569-570]. Different receivers, or even the same receiver in different communicative situations, will assign different functions to the same linguistic material, thus altering its communicative purpose. This is not the case with legal interpretation. The belief that there is one right answer to any interpretive doubt (the Dworkinian "one-right-answer" thesis) is rooted deeply in the very idea of the legal system. The communicative purpose of a legal text is always the same - to determine somebody's rights and obligations in a binding way. As a result, there is no room for alternative correct interpretations. This is not to say that there may not be competing interpretations. Quite the contrary: lawyers are constantly engaged in legal discourse, presenting claims and making arguments for their preferred interpretations. However, the whole endeavour rests on a presumption that at the end of the day, only one, correct interpretation will prevail.

In general, we recognise the concept of fidelity (or authorial intent) as an important point of contact between translation theory and legal theory that has the potential for mutual enrichment, and so is worth exploring in future research. There are also numerous other topics that require further investigation, such as the value of impartiality in the translator's and the judge's work, the problem of the addressees of legal translation and legal interpretation, the methodological tools of legal translation and legal interpretation, and the role of "precedents" in legal translation and legal interpretation.

\section{Conclusions}

To sum up, we would like to underline several crucial points of our discussion. There are different concepts of legal interpretation, where the relation between legal translation and legal interpretation depends on which of these concepts is chosen. If we adhere to the wide concept of legal interpretation (sensu largo), i.e. interpretation as understanding, we must conclude that every act of translation (by a human 
being) by definition requires interpretation. If we adhere to the narrow concept of legal interpretation (sensu stricto), i.e. interpretation as the resolution of interpretive doubts, then we have to acknowledge the differences between the two enterprises. Most notably, legal interpretation in the narrow sense is an act of resolving interpretive problems that may or may not arise in the context of particular, factual situations. It requires identifying the problem, applying an appropriate method of solving it, and arriving at the correct solution. Here, numerous similarities and dissimilarities between legal interpretation and legal translation can be observed. This paper briefly touches on some of them. There is certainly a need for more in-depth analyses. These ideally should bring together legal and translation perspectives, so that both disciplines would benefit from them. We hope that this paper provides some useful guidelines for this further research by virtue of presenting a legal theoretical perspective on the subject matter, which so far has mostly been discussed by translation scholars.

Open Access This article is licensed under a Creative Commons Attribution 4.0 International License, which permits use, sharing, adaptation, distribution and reproduction in any medium or format, as long as you give appropriate credit to the original author(s) and the source, provide a link to the Creative Commons licence, and indicate if changes were made. The images or other third party material in this article are included in the article's Creative Commons licence, unless indicated otherwise in a credit line to the material. If material is not included in the article's Creative Commons licence and your intended use is not permitted by statutory regulation or exceeds the permitted use, you will need to obtain permission directly from the copyright holder. To view a copy of this licence, visit http://creativecommons.org/licen ses/by/4.0/.

\section{References}

1. Adler, Andrew N. 1997. Translating \& Interpreting Foreign Statutes. Michigan Journal of International Law 19 (1): 37-108.

2. Bajčić, Martina. 2017. New Insights into the Semantics of Legal Concepts and the Legal Dictionary. Amsterdam-Philadelphia: John Benjamin's Publishing.

3. Baker, Mona. 1996, Corpus-based translation studies: the challenges that lie ahead. In: Terminology, LSP and Translation. Studies in Language Engineering in Honour of Juan C. Sager, ed. H.L. Somers. Amsterdam-Philadelphia: John Benjamin's Publishing, 175-186.

4. Bankowski, Zenon, Neil D. MacCormick, Roberts Summers, and Jerzy Wróblewski. 1991. On Method and Methodology. In Statutory Interpretation: A Comparative Study, ed. N. MacCormick and R. Summers, 8-28. Dartmouth: Ashgate.

5. Bestué, Carmen. 2015. Translating law in the digital age. Translation problems or matters of legal interpretation? Perspectives Studies in Translatology 24(4). https://doi.org/10.1080/0907676X.2015. 1070884.

6. Biel, Łucja and Jan Engberg. 2013. Research models and methods in legal translation. Linguistica Antverpiensia, New Series - Themes in Translation Studies 12, . 1-13.

7. Biel, Łucja. 2011. Jakość przekładu prawnego i prawniczego w świetle normy europejskiej PN-EN 15038 oraz hipotezy uniwersaliów translatorycznych. Rocznik Przekładoznawczy 6, 13-28. https:// doi.org/10.12775/RP.2011.002.

8. Cao, Deborah. 2007. Translating Law. Clevedon, New York \& Ontario: Multilingual Matters.

9. Chesterman, Andrew. 2004. Hypotheses about translation universals. In: Claims, Changes Claims, Changes and Challenges in Translation Studies: Selected contributions from the EST Congress, Copenhagen 2001, eds. G. Hansen, K. Malmkjær, D. Gile. Benjamin's Translation Library 50, 1-13. https://doi.org/10.1075/bt1.50.02che 
10. Chomsky, Noam. 1965. Aspects of the Theory of Syntax. Cambridge, Massachusetts: The Massachusetts Institute of Technology. (Polish edition: Zagadnienia teorii składni. 1982. Transl. I. Jakubczak. Wrocław-Warszawa-Kraków-Gdańsk-Łódź: Ossolineum).

11. Chromá, Marta. 2008. Semantic and Legal Interpretation: Two Approaches to Legal Translation. In Language, Culture and the Law, ed. V. Bhatia, C. Candlin, and P.E. Evangelisti, 1-13. Bern: Peter Lang.

12. Chromá, Marta. 2014. Making sense in legal translation. Semiotica 201: 121-144.

13. Chromá, Marta. Synonymy and Polysemy in Legal Terminology and Their Applications to Bilingual and Bijural Translation. Research in Language 1(9), 31-50. https://doi.org/10.2478/ v10015-011-0004-2.

14. Endicott, T.A.O. 1994. Putting interpretation in its place. Law \& Philosophy 13: 451-479. https:// doi.org/10.1007/BF02350479.

15. Endicott. Timothy. 2005, . 2011. The Value of Vagueness. In Philosophical Foundations of Language in the Law, ed. Andrei Marmor and Scott Soames, 14-30. Oxford/New York: University Press.

16. Engberg, Jan. 2002. Legal Meaning Assumptions-What are the Consequences for Legal Interpretation and Legal Translation? International Journal for the Semiotics of Law 15: 375-388. https:// doi.org/10.1023/A:1021255513221.

17. William, Eskridge. 1990. Gadamer/Statutory Interpretation. Columbia Law Review 90 (3): 609-681.

18. Fallon, Richard H. 2015. The Meaning of Legal "Meaning" and Its Implications for Theories of Legal Interpretation. University of Chicago Law Review 82 (3): 1235-1308.

19. Gadamer, Hans-Georg. 2004. Truth and Method. London \& New York: Continuum.

20. Galdia, Marcus. 2017. Lectures on Legal Linguistics. Frankfurt am Main: Peter Lang.

21. Gémar, Jean-Claude. 2014. Catching the spirit of the law: from translation to co-drafting. In Comparative Law - Engaging Translation, ed. Simone Glanert, 67-86. New York: Routlege.

22. Glanert, Simone. 2014. Law-in-translation: an assemblage in motion. The Translator 20 (3): 255272. https://doi.org/10.1080/13556509.2014.945270.

23. Grabowski, Andrzej. 2015. Clara non sunt interpretanda vs. omnia sunt interpretanda. A Never-Ending Controversy in Polish Legal Theory? Revus 26: 67-97.

24. Guastini, Riccardo. 2019. Legal Interpretation. The Realistic View. In: Encyclopedia of the Philosophy of Law and Social Philosophy, eds. M. Sellers, S. Kirste, 1-9. https://doi.org/10.1007/978-94007-6730-0_727-1.

25. Harvey, Malcolm. 2002. What's so Special about Legal Translation? Meta 47 (2): 177-185. https:// doi.org/10.7202/008007ar.

26. Husa, Jaakko. 2016. Translating Legal Language and Comparative Law. International Journal for the Semiotics of Law 30, 261-272. DOI https://doi.org/10.1007/s11196-016-9490-9

27. Jakobson, Roman. 2012 (1959). On linguistic aspects of translation. In: Theories of Translation, eds John Biguenet and Rainer Schulte, Chicago: University of Chicago Press, 144-151. https://doi.org/ 10.7208/9780226184821-015

28. Kischel, Uwe. 2009. Legal cultures-legal languages. In Translation issues in language and law, ed. Frances Olsen, Alexander Lorz, and Dieter Stein, 7-17. Basinstoke: Palgrave Macmillan.

29. Lessig, Lawrence. 1993. Fidelity in Translation. Texas Law Review 71: 1165-1268.

30. Lesznyák, Márta and Dorka Balogh. 2019. Comparative Analysis of Translations Prepared by Students with and without Legal Qualifications. Comparative Legilinguistics 37, 85-115. https://doi. org/10.14746/cl.2019.37.3.

31. Llewellyn, Karl. 1950. Remarks on the Theory of Appellate Decision and the Rules or Canons about How Statutes Are to Be Construed. Vanderbilt Law Review 3 (3): 395-406.

32. Marmor, Andrei. 2012. Textualism in Context. USC Law Legal Studies Paper 12-13: 1-18.

33. Mattila, Heikki E.S. 2013. Comparative Legal Linguistics. Language of Law, Latin and Modern Lingua Francas. London-New York: Routledge.

34. Matulewska, Aleksandra. 2017. Contrastive Parametric Study of Legal Terminology in Polish and English. Poznań: Wydawnictwo Naukowe CONTACT.

35. Mullins, Morell E. 2004. Tools, Not Rules: The Heuristic Nature of Statutory Interpretation. Journal of Legislation 30 (1): 1-76.

36. Newmark, Peter. 1988. A Textbook of Translation. Hertfordshire: Prentice Hall.

37. Nida, Eugene and Taber, Charles. 1969(1982). The Theory and Practice of Translation. Leiden: J. Brill. 
38. Nord, Christiane. 2016. Function + Loyalty: Theology Meets Skopos. Open Theology 2016 (2): 566-580.

39. Patterson, David. 1993. The Poverty of Interpretive Universalism. Towards the Reconstruction of Legal Theory. Texas Law Review 72: 1-56.

40. Piecychna, Beata. 2013. Legal Translation Competence in the Light of Translational Hermeneutics. Studies in Logic, Grammar and Rhetoric 34 (47): 141-152. https://doi.org/10.2478/slgr-2013-0027.

41. Prieto Ramos, Fernando. 2011. Developing Legal Translation Competence: an Integrative ProcessOriented Approach. Comparative Legilinguistics - International Journal for Legal Communication 5, 7-21. https://doi.org/10.14746/cl.2011.5.01.

42. Ramos, Prieto, and Fernando. 2014. Legal Translation Studies as Interdiscipline: Scope and Evolution. Meta 59 (2): 260-277. https://doi.org/10.7202/1027475ar.

43. Robin, Edina. 2016. Translation Universals Revisited. FORUM Revue internationale d'interprétation et de traduction / International Journal of Interpretation and Translation 15 (1): 51-66.

44. Rotman, Edgardo. 1995. The Inherent Problems of Legal Translation: Theoretical Aspects. Indiana International \& Comparative Law Review 6 (1): 187-196.

45. Šarcevic, Susan. 1997. The New Approach to Legal Translation. The Hague/London/Boston: Kluwer Law International.

46. Šarcevic, Susan. 2000. Legal Translation and Translation Theory: a Receiver-oriented Approach. In: La traduction juridique: Histoire, theorie(s) et pratique / Legal Translation: History, Theory/ ies, Practice. (Proceedings, Geneva, 17-19 February 2000). Bern/Geneva: ASTTI/ETI. Availible at: https://www.tradulex.com/Actes2000/sarcevic.pdf.

47. Schane, Sanford. 2002. Ambiguity and Misunderstanding in the Law. Thomas Jefferson Law Review 25 (1): 167-194.

48. Shapiro, Scott. 2006. What Is the Internal Point of View?, Fordham Law Review 75, 1157-1170. Available at: https://ir.lawnet.fordham.edu/flr/vol75/iss3/2.

49. Smith, Sylvia 1995. Culture Clash: Anglo-American Case Law and German Civil Law in Translation. In: Translation and the Law, ed. M. Morris, Amsterdam-Philadelphia: John Benjamin's Publishing Company, 179-200.

50. Soames, Scott. 2011. Toward a Theory of Legal Interpretation. New York University Journal of Law \& Liberty 6(2), 231-259. Available at: https://www.law.nyu.edu/sites/default/files/ECM_PRO_ 071606.pdf.

51. Solan, Lawrence. 2010. The Language of Statutes. Laws and Their Interpretation. Chicago-London: The University of Chicago Press.

52. Solan, Lawrence. 2018. The Interpretation of Legal Language. Annual Review of Linguistics 4: 337-355.

53. Stefaniak, Karolina. 2013. Multilingual Legal Drafting, Translators' Choices and the Principle of Lesser Evil. Meta 58 (1): 58-65. https://doi.org/10.7202/1023809ar.

54. Gizbert-Studnicki, Tomasz. 2009. Postulat jasności i zrozumiałości tekstów prawnych a dostęp do prawa. In: Prawo i jezzk, eds. A. Mroz, A. Niewiadomski, M. Pawelec. Warszawa.

55. Tiersma, Peter. 1999. Legal language. Chicago-London: The University of Chicago Press.

56. Tobor, Zygmunt. 2013. W poszukiwaniu intencji prawodawcy. Warszawa: Wolters Kluwer.

57. Walshaw, Christopher. 2012. Interpretation is Understanding and Application: The Case for Concurrent Legal Interpretation. Statute Law Review 34 (2): 101-127. https://doi.org/10.1093/slr/hms044.

58. Zeifert, Mateusz. 2018. Grammatical Issues in Judicial Interpretation - Does Legal Practice Need Linguistic Theory? Based on Polish Courts' Decisions. Comparative Legilinguistics 34, 33-51. https://doi.org/10.14746/cl.2018.34.2.

59. Zeifert, Mateusz. 2020. Prototype Theory in the Judicial Practice of the Court of Justice of the European Union. A Case Study. Comparative Legilinguisitcs 44: 93-119.

Publisher's Note Springer Nature remains neutral with regard to jurisdictional claims in published maps and institutional affiliations. 